\title{
Comparison between the risks in road safety behaviour in urban and rural areas in Latvia in 2016
}

\author{
Aija Bukova-Zideluna ${ }^{1, *}$, Anita Villerusa ${ }^{1}$, and Iveta Pudule $^{2}$ \\ ${ }^{1}$ Rīga Stradiòš University, Department of Public Health and Epidemiology, Riga, Latvia \\ ${ }^{2}$ Centre for Disease Prevention and Control, Department of Research and Health Statistics, Riga, \\ Latvia
}

\begin{abstract}
The study examined the differences between respondents in urban and rural areas in respect of their self-reported attitudes and behaviour regarding taking risks in road traffic. Data of Health Behaviour among Latvian Adult Population 2016 survey was used for analysis. Results: 83.7\% $(\mathrm{N}=1605)$ of urban respondents and $86.7 \%(\mathrm{~N}=1456)$ of rural respondents always used seatbelts in the front seat. Only $55.3 \%(\mathrm{~N}=1605)$ of urban respondents and $52.1 \%(\mathrm{~N}=875)$ of rural respondents always used seatbelts in the back seat. Odds to use seatbelts in the front seat were higher for rural population $(\mathrm{OR}=1.27 ; 95 \% \mathrm{CI}: 1.05-1.53)$. Odds to use seatbelts in the back seat were higher for urban population $(\mathrm{OR}=1.14$; 95\% CI: 1.01-1.30). Rural residents agreed more often with suggestion that it is not necessary to fasten the seatbelt on short journeys $(\mathrm{OR}=1.42$; 95\% CI: $1.15-1.75)$ and that it is not necessary to fasten the seatbelt travelling at speed less than $40 \mathrm{~km} / \mathrm{h}(\mathrm{OR}=1.22 ; 95 \% \mathrm{CI}: 1.01-1.56)$. Rural respondents agreed more often than urban respondents that that driving a car under alcohol influence increases a chance of being involved in an accident $(\mathrm{OR}=1.45 ; 95 \% \mathrm{CI}$ : $1.10-1.90)$
\end{abstract}

Key words: differences between urban and rural areas, road safety, use of seat-belt, alcohol, smoking.

\section{Introduction}

Traffic accidents were the $8^{\text {th }}$ leading cause of death for people of all ages. Approximately 1.35 million people died in road traffic accidents in the year 2016. Between 20 and 50 million more people suffered non-fatal injuries, with many incurring a disability as a result of their injury [1]. According to estimates of the European Commission approximately 135000 people sustained serious road traffic injuries on European Union roads per year. This means that for every person killed in traffic accidents, five more suffered serious injuries in European Union countries. Serious injuries were not only more common but also often more costly to society because of long-time rehabilitation and healthcare needs. It is estimated that approximately $8 \%$ of road fatalities occurred on motorways, $37 \%$ happened in urban areas and 55\% on rural roads in the European Union in 2017 [2]. It has been estimated that safety belts reduce risk of fatality of front-seat occupants of passenger cars by 45 percent relative to those who choose not to wear them [3]. Failure to use seatbelts is the second biggest

\footnotetext{
* Corresponding author: aija.bukova@rsu. Iv
} 
cause of road deaths, after speeding and ahead of drink-driving. A study carried out for the European Commission has concluded that, in the best-case scenario, actions targeting the use of seatbelts would save 5500 lives per year in the European Union [4].

Although progress is being made in several areas, vehicle occupant fatalities have not been falling in line with casualty reduction targets for Latvia. Latvia was the country with the second highest fatality rate among European Union countries in 2014 (around 10.6 fatalities per 100000 population). Fatal road traffic accidents in rural areas are over-represented compared to other European countries. The use of safety seatbelts by drivers, front-seat passengers and rear-seat passengers is compulsory in Latvia. However, the rate of wearing seatbelts is lower in Latvia than in other European Union countries [5].

The prevailing risk of traffic fatalities and casualties differs between urban and rural areas. Several reasons have been suggested to explain this including road design, the proximity to emergency medical services and human factors. The main task of the study was to examine the differences between respondents in urban and rural areas in respect of their self-reported attitudes and risk-taking behaviour in road traffic.

\section{Methods}

The study used the data from the survey of year 2016 regarding Health Behaviour among the Latvian Adult Population. The study sample for the survey was selected using a combined sampling method - stratified random sampling and the quota method. The sample was selected from the general population of Latvian residents aged from 15 to 74 (Data of the 2011 Population and Housing Census in Latvia). The total sample size consisted of 3596 people - a representative sample. The sample was stratified by gender, age, place of residence and nationality. Data was collected by face to face standardised interviews.

The survey included self-reported questions regarding traffic safety:

- Do you use safety belts when driving in the front seat?

- Do you use safety-belts in the back seat?

- Do you agree with the following statements?

- It is not necessary to fasten the seatbelt in short trips by car.

- It is not necessary to use the seatbelt, when travelling at speed less than $40 \mathrm{~km} / \mathrm{h}$.

- Driving a car under alcohol influence increases my chance of being involved in an accident.

For all respondents demographic and socioeconomic information - gender, age and education level - was collected and analysed.

The data was analysed using descriptive statistics, Pearson's chi-squared and calculations of statistical reliability using SPSS for Windows 23.0. T-test and logistic regression analyses were conducted to compare the unsafe behaviour of road users with others in terms of sociodemographic, health-related and behavioural outcomes. The $95 \%$ confidence interval (CI) was used to estimate the precision of the odds ratio (OR).

\section{Results}

$83.7 \%(\mathrm{~N}=1605)$ of urban respondents and $86.7 \%(\mathrm{~N}=1456)$ of rural respondents always used seatbelts in the front seat. The use of seatbelts in the front seat was higher for rural females compared to males, higher in the age group 35-44 and those who had had more years of education. The use of seatbelts in the front seat was higher in rural population for all age groups, except for the age group of 55-64, in which the use of seatbelts was higher for 
Table 1. Characteristics of respondents who always use a seat belt in the front seat.

\begin{tabular}{|l|c|c|c|c|}
\hline \multicolumn{2}{|c|}{ Factor } & $\begin{array}{c}\text { Number (\% of } \\
\text { cases) in urban } \\
\text { area }\end{array}$ & $\begin{array}{c}\text { Number (\% of } \\
\text { cases) in rural } \\
\text { area }\end{array}$ & $p$-value \\
\hline \multirow{4}{*}{ Gender } & Male & $626(81.9)$ & $607(84.7)$ & 0.09 \\
\cline { 2 - 5 } & Female & $979(84.9)$ & $849(86.4)$ & $0.01 *$ \\
\cline { 2 - 5 } & Total & $1605(83.7)$ & $1456(86.7)$ & $0.00^{*}$ \\
\hline \multirow{4}{*}{ Age } & $15-24$ & $220(83.0)$ & $245(85.2)$ & 0.29 \\
\cline { 2 - 5 } & $25-34$ & $301(86.7)$ & $280(89.7)$ & 0.14 \\
\cline { 2 - 5 } & $35-44$ & $285(87.2)$ & $295(93.4)$ & $0.00^{*}$ \\
\cline { 2 - 5 } & $45-54$ & $287(86.7)$ & $233(87.9)$ & 0.38 \\
\cline { 2 - 5 } & $55-64$ & $294(82.1)$ & $220(81.2)$ & 0.42 \\
\hline \multirow{3}{*}{ Length of education } & $0-9$ years & $123(68.3)$ & $148(74.7)$ & 0.10 \\
\cline { 2 - 5 } & $10-12$ years & $621(80.1)$ & $602(85.4)$ & $0.00 *$ \\
\cline { 2 - 5 } & 13 and more & $861(89.5)$ & $706(91.0)$ & 0.17 \\
\hline
\end{tabular}

*Differences are statistically significant.

urban respondents. The analysis of urban respondents compared to rural respondents showed statistically significant differences (Pearson's chi-squared test $\chi^{2}=20.97 ; p$-value $=0.01$ ). The odds of using seatbelts in the front seat were 1.27 times higher for the rural population $(\mathrm{OR}=1.27$; 95\% CI: $1.05-1.53)$. The characteristics of respondents who always used a seat belt in the front seat according to gender, age and level of education is shown in Table 1.

$55.3 \%(\mathrm{~N}=1605)$ of urban respondents and $52.1 \%(\mathrm{~N}=875)$ of rural respondents always used seatbelts in the back seat. The use of seatbelts in the back seat was lower for urban males compared to females, higher in the age group 45-54 and those who had had more years of education. The use of seatbelts in the back seat was higher in urban population for all age groups, except for the age group of 24-44, where the use of seatbelts was higher for rural respondents. The analysis of urban respondents who always used seatbelts in the back seat compared to rural respondents showed statistically significant differences (Pearson's chi-squared test $\chi^{2}=15.86 ; p$-value $=0.04$ ). The odds of using seatbelts in the back seat were 1.14 times higher for the urban population $(\mathrm{OR}=1.14 ; 95 \% \mathrm{CI}: 1.01-1.30)$. The characteristics of respondents who always used a seat belt in the back seat according to gender, age and level of education is shown in Table 2.

$9.6 \%(\mathrm{~N}=184)$ of urban respondents and $13.1 \%(\mathrm{~N}=220)$ of rural respondents agreed with the idea that it was not necessary to fasten seat belt for short journeys. Rural residents men, in the age group between 15-24 and those who had had less years of education agreed more with this statement compared to urban residents. The proportion of respondents who agree with this false statement was higher in rural population for all age groups, except in the 24-44 age group, where the proportion was higher for urban respondents.

The analysis of urban respondents in total compared to rural respondents showed statistically significant differences (Pearson's chi-squared test $\chi^{2}=14.04 ; p$-value $=0.001$ ). The proportion of rural population, with the false belief in the use of seat belts for short trips, was larger $(\mathrm{OR}=1.42 ; 95 \% \mathrm{CI}$ : $1.15-1.75)$. The characteristics of respondents who agreed with this statement according to gender, age and level of education is shown in Table 3.

$7.0 \%(\mathrm{~N}=135)$ of urban respondents and $8.5 \%(\mathrm{~N}=142)$ of rural respondents agreed that it was not necessary to fasten seatbelts while travelling at a speed of less than $40 \mathrm{~km} / \mathrm{h}$. 
Table 2. Characteristics of respondents who always use a seatbelt in the back seat.

\begin{tabular}{|l|c|c|c|c|}
\hline \multicolumn{2}{|c|}{ Factor } & $\begin{array}{c}\text { Number (\% of } \\
\text { cases) in urban } \\
\text { area }\end{array}$ & $\begin{array}{c}\text { Number (\% of } \\
\text { cases) in rural } \\
\text { area }\end{array}$ & $p$-value \\
\hline \multirow{4}{*}{ Gender } & Male & $381(49.9)$ & $321(44.8)$ & $0.02 *$ \\
\cline { 2 - 5 } & Female & $680(59.0)$ & $554(57.6)$ & 0.27 \\
\cline { 2 - 5 } & Total & $1065(55.3)$ & $875(52.1)$ & $0.28^{*}$ \\
\hline \multirow{4}{*}{ Age } & $15-24$ & $147(55.5)$ & $133(46.2)$ & $0.03 *$ \\
\cline { 2 - 5 } & $25-34$ & $200(53.8)$ & $172(55.1)$ & 0.52 \\
\cline { 2 - 5 } & $35-44$ & $183(56.0)$ & $190(60.1)$ & 0.29 \\
\cline { 2 - 5 } & $45-54$ & $189(57.1)$ & $133(50.2)$ & $0.04 *$ \\
\cline { 2 - 5 } & $55-64$ & $194(54.2)$ & $133(49.1)$ & 0.20 \\
\hline \multirow{3}{*}{ Length of education } & $0-9$ years & $88(48.9)$ & $99(50.0)$ & 0.83 \\
\cline { 2 - 5 } & $10-12$ years & $419(54.1)$ & $353(50.1)$ & 0.13 \\
\cline { 2 - 5 } & 13 and more & $554(57.6)$ & $423(54.5)$ & 0.20 \\
\hline
\end{tabular}

*Differences are statistically significant.

Table 3. Characteristics of respondents who agree with the statement - it is not necessary to fasten seatbelts on short journeys.

\begin{tabular}{|l|c|c|c|c|}
\hline \multicolumn{2}{|c|}{ Factor } & $\begin{array}{c}\text { Number (\% of } \\
\text { cases) in urban } \\
\text { area }\end{array}$ & $\begin{array}{c}\text { Number }(\% \text { of } \\
\text { cases) in rural } \\
\text { area }\end{array}$ & $p$-value \\
\hline \multirow{4}{*}{ Gender } & Male & $108(14.1)$ & $141(19.7)$ & $0.00 *$ \\
\cline { 2 - 5 } & Female & $76(6.6)$ & $79(8.2)$ & 0.15 \\
\cline { 2 - 5 } Age & Total & $184(8.6)$ & $220(13.1)$ & $0.00^{*}$ \\
\hline \multirow{4}{*}{ Length of education } & $15-24$ & $36(13.6)$ & $55(19.1)$ & $0.04 *$ \\
\cline { 2 - 5 } & $25-34$ & $45(13.0)$ & $32(10.3)$ & 0.28 \\
\cline { 2 - 5 } & $35-44$ & $36(11.0)$ & $39(12.2)$ & 0.60 \\
\cline { 2 - 5 } & $45-54$ & $28(8.5)$ & $34(12.8)$ & 0.08 \\
\cline { 2 - 5 } & $55-64$ & $23(6.4)$ & $36(13.3)$ & $0.00 *$ \\
\cline { 2 - 5 } & $0-9$ years & $31(17.2)$ & $37(18.7)$ & 0.71 \\
\cline { 2 - 5 } & 13 years & $78(10.1)$ & $113(16.0)$ & $0.00 *$ \\
\hline
\end{tabular}

*Differences are statistically significant.

Rural residents in the age group between 45-54 and those who had had more years of education agreed more with this statement compared to urban residents. The analysis of urban respondents compared with rural respondents showed statistically significant differences (Pearson's chi-squared test $\chi^{2}=15.89 ; p$-value $=0.04$ ). Rural residents agreed more often with the idea that it was not necessary to fasten seatbelts while travelling at a speed of less than $40 \mathrm{~km} / \mathrm{h}(\mathrm{OR}=1.22 ; 95 \% \mathrm{CI}: 1.01-1.56)$. The characteristics of respondents who agreed with this statement according to gender, age and level of education are shown in Table 4.

$92.4 \%(\mathrm{~N}=1772)$ of urban respondents and $94.6 \%(\mathrm{~N}=1589)$ of rural respondents agreed that driving a car while under the influence of alcohol increased the chances of being 
Table 4. Characteristics of respondents who agree with the statement - it is not necessary to use seatbelts, while travelling at a speed of less than $40 \mathrm{~km} / \mathrm{h}$.

\begin{tabular}{|l|c|c|c|c|}
\hline \multicolumn{2}{|c|}{ Factor } & $\begin{array}{c}\text { Number (\% of } \\
\text { cases) in urban } \\
\text { area }\end{array}$ & $\begin{array}{c}\text { Number }(\% \text { of } \\
\text { cases) in rural } \\
\text { area }\end{array}$ & $p$-value \\
\hline \multirow{4}{*}{ Gender } & Male & $77(10.1)$ & $85(11.9)$ & 0.27 \\
\cline { 2 - 5 } & Female & $58(5.0)$ & $57(5.9)$ & 0.36 \\
\cline { 2 - 5 } & Total & $135(7.0)$ & $142(8.5)$ & 0.11 \\
\hline \multirow{4}{*}{ Age } & $15-24$ & $28(10.6)$ & $35(12.2)$ & 0.56 \\
\cline { 2 - 5 } & $25-34$ & $33(9.5)$ & $23(7.4)$ & 0.32 \\
\cline { 2 - 5 } & $35-44$ & $27(8.3)$ & $24(7.6)$ & 0.76 \\
\cline { 2 - 5 } & $45-54$ & $17(5.1)$ & $24(9.1)$ & $0.04 *$ \\
\cline { 2 - 5 } & $55-64$ & $21(5.9)$ & $23(8.5)$ & 0.20 \\
\hline \multirow{4}{*}{ Length of education } & $0-9$ years & $23(12.8)$ & $22(11.8)$ & 0.36 \\
\cline { 2 - 5 } & $10-12$ years & $55(7.1 \%)$ & $74(10.5)$ & $0.01 *$ \\
\cline { 2 - 5 } & 13 and more & $57(5.9)$ & $46(5.9)$ & 0.53 \\
\hline
\end{tabular}

*Differences are statistically significant.

Table 5. Characteristics of respondents who agree with the statement - driving a car under while under the influence of alcohol increases the chances of being involved in an accident.

\begin{tabular}{|c|c|c|c|c|}
\hline \multicolumn{2}{|c|}{ Factor } & $\begin{array}{c}\text { Number }(\% \text { of } \\
\text { cases) in urban } \\
\text { area }\end{array}$ & $\begin{array}{c}\text { Number }(\% \text { of } \\
\text { cases) in rural } \\
\text { area }\end{array}$ & $p$-value \\
\hline \multirow{4}{*}{ Gender } & Male & $710(92.9)$ & $673(93.9)$ & 0.47 \\
\cline { 2 - 5 } & Female & $1062(92.1)$ & $916(95.2)$ & $0.00^{*}$ \\
\cline { 2 - 5 } & Total & $1772(92.4)$ & $1589(94.6)$ & $0.00^{*}$ \\
\hline \multirow{4}{*}{ Age } & $15-24$ & $239(90.2)$ & $264(91.7)$ & 0.54 \\
\cline { 2 - 5 } & $25-34$ & $322(92.9)$ & $294(94.2)$ & 0.45 \\
\cline { 2 - 5 } & $35-44$ & $303(92.7)$ & $304(96.2)$ & 0.05 \\
\cline { 2 - 5 } & $45-54$ & $317(95.8)$ & $250(94.3)$ & 0.42 \\
\hline \multirow{4}{*}{1264} & $55-64$ & $329(91.9)$ & $262(96.7)$ & $0.01 *$ \\
\cline { 2 - 5 } & $0-9$ years & $158(87.8)$ & $181(91.4)$ & 0.25 \\
\cline { 2 - 5 } & $10-12$ years & $698(90.1)$ & $666(94.5)$ & $0.00^{*}$ \\
\cline { 2 - 5 } & 13 and more & $916(95.2)$ & $742(95.6)$ & 0.69 \\
\hline
\end{tabular}

*Differences are statistically significant.

involved in an accident. Rural residents - females, in the age group between 55-64 and those who had had 10-12 years of education - agreed more with this statement compared to urban residents. The analysis of urban respondents compared to rural respondents showed statistically significant differences (Pearson's chi-squared test $\chi^{2}=14.01 ; p$-value $=0.05$ ). Rural residents agreed more often with the false idea that driving a car while under the influence of alcohol increased the chances of being involved in an accident (OR $=1.45 ; 95 \%$ CI: 1.10-1.90). The characteristics of respondents who agreed with this suggestion according to gender, age and level of education is shown in Table 5. 


\section{Discussion}

This study has provided the analysis of the behaviour and attitudes regarding road safety displayed by urban and rural adults. Despite the existing seat belt legislation, public campaigns and regular police monitoring both of urban and rural roads, a large proportion of the population did not use seatbelts in Latvia, especially in the back seat. While $83.7 \%$ of urban respondents and $86.7 \%$ of rural respondents always used seatbelts in the front seat, only $55.3 \%$ of urban respondents and $52.1 \%$ of rural respondents always used seatbelts in the back seat. According to the study carried out for the European Commission the rates of wearing seatbelts varies from $36 \%$ to $91 \%$ in urban areas in the European Union [4]. The relatively low rates of seatbelts in Latvia have been accepted as one of the priorities in traffic safety because of the high fatality and injury rates in traffic accidents compared to other European Union countries [6].

Similar to other studies of practices regarding the use of seatbelts, demographic factors such as age, gender and education levels were associated with the lower use of seatbelts [7-9]. However, other surveys regarding the use of seatbelts emphasize that the 18 to 25 age group tend to use seatbelts less than all other age groups. This study shows those least likely to use seatbelt in the front seat are between 55 and 64 years old and 15 to 24 years old rural respondents. It is possible that respondents in the age group of 55-64 still remember cars without seatbelts and times when it was not necessary to fasten them/ Consistent to other researches $[8,10]$ rural males were less likely to report that they always used seat belt in the front and in the back seat compared to females. Consistent with other studies [11] there proved to be a link between levels of education and the use of seatbelts especially the responds who had had 10-12 years of education. Less use of seat belts in rural areas compared with urban areas is a factor that has contributed to the increased risk of deaths in traffic accidents in rural areas.

Apart from the demographic and socioeconomic characteristics of respondents, there were also other factors such as attitudes, beliefs, and intentions which influenced the use of seatbelts [12]. Negative attitudes and beliefs regarding the effectiveness of the use of seatbelts had a negative relationship in respect of the use of seatbelts [13]. Using seatbelts can be described as a habitual behaviour that is mainly affected by the gender, age, socioeconomic situation of a person combined with the perceived usefulness of seatbelts in a possible accident [14]. This study has shown that rural residents agreed more often with the false statement that it was not necessary to fasten seatbelts on short journeys and that it was not necessary to fasten the seatbelt while travelling at a speed of less than $40 \mathrm{~km} / \mathrm{h}$. At the same time rural residents agreed more often with the idea that driving a car under the influence of alcohol increased the chance of being involved in an accident.

\section{Conclusions}

Road traffic accidents, injuries and deaths are generally related to preventable risk factors. In this study the behaviour and attitudes regarding road safety were analysed based on the place of residence, demographic and socioeconomic factors. It can be concluded that there is not enough awareness of road safety in the community. The study has demonstrated that there is a greater risk of being involved in a traffic accident in a rural area than in an urban one. Consequently, more effort should be put in encouraging individuals in rural areas to use seat belts in the rear seat of the car, particularly in among males, aged between 15 to 24 and those who have studied for 10 to 12 years.

It is generally recognised that the use of seatbelts can prevent injuries and fatalities. Law enforcement and educational efforts need to be used to increase the use of seatbelts and to 
reduce accidents in rural areas. Stronger laws regarding the use of seatbelts and targeted enforcement may also influence the beliefs and attitudes regarding the use of seatbelts in the back seat. Combining public campaigns and enforcement with educational and development could influence behaviour among certain critical groups and further improve road safety behaviour. This research can be used to plan and design educational programmes and campaigns focused on groups at risk in order to change the road safety culture from one that is risk receptive to one that is risk protective.

\section{References}

[1] World Health Organization, Global status report on road safety, (2018). Available at: https://www.who.int/violence_injury_prevention/road_safety_status/ 2018/en [viewed 31.01.2019]

[2] European Commission Road safety in the European Union, Trends, statistics and main challenges (2018). Available at: https://ec.europa.eu/transport/road_ safety/sites/roadsafety/files/vademecum_2018.pdf [viewed 31.01.2019]

[3] Commission of the European Communities, Proposal for a Directive of the European Parliament and of Council about facilitating cross-border enforcement in the field of road safety, Brussels, 351/2 (2008)

[4] European Commission, Proposal for a directive of the European Parliament and of the Council facilitating cross-border enforcement in the field of road safety (2008). Available at: https://ec.europa.eu/transport/road_safety/sites/ roadsafety/files/enforcement/doc/full_impact_assessment_en.pdf [viewed 31.01.2019]

[5] European Road Safety Observatory, Road Safety Country Overview - Latvia, 1-16 (2016)

[6] Cabinet Order No. 180 “On Road Traffic Safety Plan for 2017-2020” (2017). Available at: https://likumi.lv/ta/en/en/id/289986 [viewed 31.01.2019]

[7] L.F. Beck, R.A. Shults, Seat belt use in states and territories with primary and secondary laws - United States, 2006, J. Saf. Res. 40(6), 469-472 (2009)

[8] T.W. Strine, L.F. Beck, J. Bolen, C. Okoro, S. Dhingra, L. Balluz, Geographic and sociodemographic variation in self-reported seat belt use in the United States, Accident Analysis and Prevention 42(4), 1066-1071 (2010)

[9] J. Tison, A.F. Williams, N.K. Chaudhary, Daytime and nighttime seat belt use by fatally injured passenger vehicle occupants. National Highway Traffic Safety Administration, Washington (2010)

[10] F. Laurie, J. Downs, M.R. Stevens, et al., Rural and Urban Differences in PassengerVehicle-Occupant Deaths and Seat Belt Use Among Adults, MMVR Surveillance Summaries 66(17), 1-13 (2017)

[11] K. Lipovac, M. Tesic, B. Maric, et al., Self-reported and observed seat belt use - A case study: Bosnia and Herzegovina, Accident Analysis and Prevention 84, 74-82 (2015)

[12] E.J. Chliaoutakis, C. Gnardellis, I. Drakou, C. Darviri, V. Sboukis, Modelling the factors related to the seatbelt use by the young drivers of Athens, Accident Analysis and Prevention 32, 815-825 (2000)

[13] D.J. Begg, D.J. Langley, Seat-belt use and related behavior among young adults, J. Saf. Res. 31, 211-220 (2000)

[14] F. Calisir, M.R. Lehto, Young drivers' decision making and safety belt use, Accident Analysis and Prevention 34, 793-805 (2002) 